\title{
Loss of apical vertebral derotation in adolescent idiopathic scoliosis: 2-year follow-up using multi-planar reconstruction computed tomography' [by G. Cui, K. Watanabe, Y. Nishiwaki, N. Hosogane, T. Tsuji, K. Ishii, M. Nakamura, Y. Toyama, K. Chiba, M. Matsumoto; Eur Spine J (2012) Jun;21(6):1111- 20]
}

\author{
Adrian Gardner
}

Received: 3 April 2012/Accepted: 16 December 2012/Published online: 4 January 2013

(C) Springer-Verlag Berlin Heidelberg 2013

\section{Dear Sir,}

I wish to raise with you a concern about the methodology and interpretation of results from the recent paper 'Loss of apical vertebral derotation in adolescent idiopathic scoliosis: 2-year follow-up using multi-planar reconstruction computed tomography' by G. Cui and co-workers [1].

The results presented in the paper refer to a significant difference between the Cobb angle measured immediately after surgery and 2 years later, a change in Cobb angle of $2.5^{\circ} \pm 1.6^{\circ}$. This result appears to be calculated through the difference between the mean Cobb angle and range from the two time points.

What seems not to be accounted for is the known intraand interobserver measurement error inherent in the use of the Cobb angle to measure scoliosis. No plain radiograph is ever exactly the same as the last as the patient never stands in the same position and the X-ray beam is centred slightly differently. This can be seen in Fig. 1 images $b$ and $c$ where the rotation of the body to the coronal plane is not the same indicated by the different shapes and sizes of the iliac crests and the location of the pedicles of L4 relative to the vertebral body. The X-ray beam has also been centred differently shown by the different angulation of the pedicle screws. The measurement of the Cobb angle is then dependant on manually marking reference points on the radiograph to measure against and this will be slightly different on every occasion. The error for Cobb measurement is reported as between $3^{\circ}$ and $9^{\circ}[2-5]$. Thus a change

A. Gardner $(\bowtie)$

The Royal Orthopaedic Hospital NHS Foundation Trust, Bristol Road South, Northfield, Birmingham B31 2AP, UK e-mail: adrian.gardner@nhs.net in Cobb angle $<3^{\circ}$ cannot be accepted as a true change as it is within the accepted margins of error.

The change in Cobb angle measured here may be a statistically significant result but it cannot be a clinically significant result. The measured changes are within the published measurement error and cannot be accepted as a true change. The conclusion of a loss of correction is thus incorrect. Unfortunately the Cobb angle, whilst used throughout the world as the way of measuring spinal deformity, has significant flaws, which need to be accounted especially when used with small changes in angulation.

Conflict of interest None.

\section{References}

1. Cui G, Watanabe K, Nishiwaki Y, Hosogane N, Tsuji T, Ishii K, Naakamura M, Toyama Y, Chiba K, Matsumoto M (2012) Loss of apical vertebral derotation in adolescent idiopathic scoliosis: 2-year follow-up using multi-planar reconstruction computed tomography. Eur Spine J 21(6): 1111-1120

2. Adam C, Izatt M, Harvey J, Askin G (2005) Variability in Cobb angle measurements using reformatted computerized tomography scans. Spine 30:1664-1669

3. Carman D, Browne R, Birch J (1990) Measurement of scoliosis and kyphosis radiographs. J Bone Joint Surg 72A:328-333

4. Dutton K, Jones T, Slinger B, Scull E, O’Connor J (1989) Reliability of the Cobb angle index derived by traditional and computer assisted methods. Australas Phys Eng 12:16-23

5. Goldberg M, Poitras B, Mayo N, Labelle H, Bourassa R, Cloutier $\mathrm{R}$ (1988) Observer variation in assessing spinal curvature and skeletal development in adolescent idiopathic scoliosis. Spine 13:1371-1377 